\title{
Embedding learning development; a model for collaborative practice
}

\section{Laura Minogue}

St Mary's University, Twickenham, UK

\section{Carole Murphy}

St Mary's University, Twickenham, UK

\section{Kim Salmons}

St Mary's University, Twickenham, UK

\begin{abstract}
In 2016, the Learning Development Team at St Mary's University was awarded a prize for teaching excellence for its report on 'the collaborative delivery of embedded academic skills development programmes within subject modules'. The report detailed the planning and delivery of embedded activities across Schools in which academic skills were tailored to subject specific module content. The success of the report resulted in long-term investment in the Learning Development Team and positioned embedded academic learning as an integral part of the university's corporate plan. This paper presents the results of a small-scale research study to evaluate an embedded academic skills module in Criminology and Sociology delivered at Level 4. The impact of this embedded module has been measured through semi-structured interviews with students, the subject lecturer and learning development lecturer. The final self-evaluation assessment was also analysed to understand more fully how students had developed over the course of the module. Results clearly demonstrate that embedding academic skills into the Criminology and Sociology programme had an impact on student confidence, belonging and retention. The outcome is an 'impact-tested' accredited skills module that can be adapted and used by other learning development teams.
\end{abstract}

Keywords: Academic literacies; embedded skills; learning development; collaborative practice. 


\section{Introduction}

As Wingate has identified, university cohorts have changed significantly since the early 1990s 'with a larger share of students from non-traditional backgrounds' (2006, p.457). Many of these students feel unprepared for higher education and do not perceive themselves to have the appropriate skills for success (Gamache, 2002; Haggis, 2006). As the academic literacies model acknowledges:

Learning in higher education involves adapting to new ways of knowing (Lea and Street, 1998, p.158).

Lecturers have implicit knowledge about their discipline which needs to be made explicit to students. Students need to acquire not just knowledge about their discipline but the right skills to engage with and make sense of the core language and discourses.

Traditionally learning development has focused specifically on widening participation (WP) students. At St Mary's University Twickenham, where the research was conducted, two thirds of the entire cohort 2016-2017 were WP $(4,110$ out of 6,135$)$ with the first year cohort alone comprising nearly $72 \%$ WP students $(3,800$ out of 3,967$)$. In the past, universities have attempted to accommodate these students by providing study skills as separate bolt-on sessions; the 'deficit' model. However these sessions, which are often drop-in or extra-curricular, have proved ineffective as they separate study skills from the process and content of learning (Wingate, 2006). More importantly, making these sessions extra-curricular tends to position study skills as a remedial activity for referred students who are 'failing' (Cottrell, 2001, p.40).

Instead of separating skills from content it is more effective for subject lecturers and learning development lecturers to work together to design, deliver and assess modules; an approach increasingly recognised and advocated by researchers (Wingate et al., 2011; Thies, 2012). There has been a growing consensus that skills need to be embedded in the curriculum in this way, making them available to all students and ideally subject to assessment (Cottrell, 2001; Wingate, 2006). The advantage of embedding skills into the curriculum is that all students are exposed to learning development opportunities. Since it is often only the more able students who pro-actively seek extra-curricular guidance 
(Durkin and Main, 2002), embedded literacy skills enable lecturers to access the hard to reach students. Embedding literacy skills in such a way that students acquire both content knowledge and the relevant tools for understanding is essential and can impact significantly on confidence.

Although the need for embedded literacy provision for students has been widely acknowledged (Cottrell, 2001; Wingate, 2006; Black and Rechter, 2013; McWilliams and Allan, 2014), there is still limited take up in many universities. This paper presents an embedded skills module designed and delivered through a successful partnership between learning development and the subject specialist lecturers (Criminology and Sociology). The skills and experience plus the collaborative working relationship between both lecturers were crucial in developing the module and in ensuring positive outcomes for students. This module is one of a few that have been incorporated into the core curriculum at St Mary's University, Twickenham.

\section{Context and design of skills module}

The embedded skills module was delivered in the School of Arts and Humanities in the first semester of Level 4 (September to December 2016). The module was compulsory for those studying single honours Criminology and Sociology (16 in total) and was offered as an option module for students on the Sociology Programme. The module was delivered to a total of 33 students and taught over 30 hours as a two-hour weekly seminar/interactive lecture carrying a value of 20 credits. Included within this was: a week delivered by the Library and the Technology Enhanced Learning Team; a 'reading week'; a tutorial week; and a week delivered by Careers. The remainder was made up of independent study and guided learning.

The core aim of the module was to introduce students to studying Criminology and Sociology with an emphasis on the specific skills and approaches necessary for successful study. The objectives were as follows:

1. Illustrate how to find, use and evaluate criminological and sociological resources including legislation, books, journals, statistics, media and web sources. 
2. Develop criminological and sociologically informed critical thinking, practical and conceptual skills.

3. Provide a regular and directed forum for the free exchange of criminological/sociological ideas and sharing of relevant information.

4. Provide a structured opportunity for the development and enhancement of essential academic skills required to successfully complete a degree in Criminology and Sociology.

The need for a skills module was identified by the Programme Director for Criminology and Sociology in 2015. During her 14 years of experience as a lecturer in higher education $(\mathrm{HE})$, she had noted an increasing lack of preparedness amongst students for study in an HE context. This was reflected in poor writing and evaluation skills which affected student confidence and may have impacted on retention. The content of the study skills module was loosely guided by the publication 'Criminology Skills' (Finch and Fafinski, 2012). This publication identified key skills such as: reading, note-taking, time management, personal learning development, writing skills, grammar and punctuation, integrating quotations, referencing, and evaluation of media, statistics and internet sources. These were delivered using subject content with the objective of developing critical and evaluative skills. Rather than embed the study skills into an existing module, the Programme Director for Criminology authorised and validated a new credit bearing module (designed in collaboration with the Learning Development Lecturer for Arts and Humanities) and this was launched as a pilot with the view to writing similar subject-specific modules on other programmes in Arts and Humanities. The module is worth 20 credits and is taken as one of six modules in the first year, leading to an award of 120 credits overall if all modules are passed.

\section{Assessment criteria}

The module was assessed using formative and summative methods. The first formative assessment was a 250 word 'introduction to the critical review' which formed part of the summative assessment: a 750/1000 word critical review (40\%) due at the end of the first reading week. The second assignment was an 'evaluation of web sources' (50\%) and a 'self-evaluation of learning' (10\%) due at the end of the semester. Each week students were assigned reading tasks in preparation for the following week (guided learning). 


\section{Schedule of delivery}

Week one: Introduction/basic academic skills: reading, note taking, asking questions, selfevaluation.

Week two: Library and TEL (Technology Enhanced Learning Department).

Week three: Writing skills: grammar/punctuation/academic style.

Week four: Understanding critical evaluation and skills for writing a critical review.

(Formative assessment: to write a 250 -word introduction to a critical review).

Week five: Feedback session using peer review on introduction to critical review.

Week six: Reading week. Individual tutorials with the subject lecturer and learning development lecturer.

Week seven: Careers presentation.

Week eight: Researching and evaluating media and web sources.

Week nine: Understanding different mediums for feedback and using feedback on formative and summative assignments to feed forward to the next assignment.

Week ten: Statistics.

Week eleven: Analysing the assignment question (evaluating web sources). Tackling the assignment (self-evaluation assessment).

Week twelve: Plagiarism and referencing; individual tutorials.

Week thirteen: Individual tutorials.

\section{Method of delivery}

The sessions were delivered by either the learning development lecturer or the subject lecturer and, on six of the weeks, the lecturers delivered together. The collaborative nature of the teaching delivery reflects research showing that there is a need for an 'integrated relationship between writing and knowledge construction' in study skills modules (Somerville and Crème, 2005, p.18) and this can only be achieved through 'substantial liaison with the teaching staff' (Durkin and Main, 2002, p.27). This need to relate study skills to subject content is a response to research indicating that decontextualizing study skills away from the subject area negates 'the purpose of what [the student is] doing' (Gamache, 2002, p.278). Furthermore, students are more engaged when they understand that study skills are part of their holistic subject learning and directly related to their discipline: 
Findings from research seem to suggest that there is not a single academic discourse community with unified standards and expectations but rather that every specific discipline has its own conventions, values and practices. (Angelova and Riazantseva, 1999, p. 93, cited in Durkin and Main, 2002, p. 26).

The students were given a module handbook and access to module resources on the virtual learning page (MyModules). Presentations were used to structure the sessions with integrated group work and individualised feedback sessions. In week one, the students were asked to fill in a self-evaluation questionnaire asking them to identify their strengths and weaknesses. The self-evaluation was revisited in week ten when the students were assigned a summative assessment piece which asked them to reflect and evaluate their progress. This reflective exercise was not only used to develop the students' ability to evaluate their own learning within the module but to enable them to consider reflection as a part of their academic development throughout their university experience and beyond (Somerville and Crème, 2005). The first thirty minutes of each session covered the specific area of study for that week. For example, in week one on note taking and reading, strategies for both were presented and then the students were asked to engage in a reading and note taking session. Students had a choice of two texts: Debbie Taylor's 'Women: Work and Domestic Responsibility' and Mark E. Mishkind's 'A Man and his Sense of Self' (both texts are contained in Giddens, 1995, Human Societies: A Reader). Having had the opportunity to read both, the students were later asked to choose which of the two texts they would like to evaluate for their summative critical review (assessment one).

In preparation for the sessions, the students were required to read chapters of the key text, Finch and Fafinski (2012). In week three ('How to write'), the students were asked to complete a formative assessment exercise on spelling, punctuation and sentence construction using a range of on-line and paper based tools. In week four ('Critical thinking'), a combination of presentation, question and answer sessions and a formative exercise where students had to write the introduction to their critical review were employed. The students were then asked to create a draft of the critical review for the following week, which would be peer-reviewed. There were some drawbacks with this method of formative assessment in that not all the students completed the drafts. This made the peer review and the one-to-one feedback sessions (in class) difficult to conduct. 
The lower than usual attendance for this week (22 students) indicated that those students who had not attempted the draft may have decided not to attend. This resulted in not all students receiving formative feedback.

In week nine there was a class feedback/feedforward session which restated and reminded the students of the implicit aims of the module. Students were encouraged to reflect carefully on their feedback and to use it explicitly when planning and writing future assignments. The guiding principle of this work was the development of confidence in the student. As identified by Stankov et al. (2014), confidence is the key, non-subject based, indicator of achievement.

Week nine of the module was redesigned after marking the critical review (assessment one) as it became clear that students were struggling with referencing. Although this had been discussed in week one, a deeper and more guided approach was clearly necessary. This was combined with a discussion on plagiarism. Weeks eight and ten focussed on the first part of the second summative assessment ('2a. Evaluation of media statistics/web sources'). This primarily comprised presentations and question and answer sessions with group work on sourcing relevant websites. On reflection it was decided that, for this session to be the most effective it can be, future classes would take place in the computer room to enable students to research sources live. Although many students bring their laptops into classes, a lecturer-guided approach on an interactive screen would prove more engaging and relevant for the students.

\section{Attendance}

The sessions were delivered between 4pm and 6pm on a Tuesday as interactive lectures and workshops over 12 weeks. The timing is significant because the skills module was timetabled directly after a three hour Sociology module, which was compulsory for all students. There were concerns about the impact on attendance, which did not transpire and attendance was consistently high. Week two was delivered by the Library and the Technology Enhanced Learning team; weeks six and twelve were a reading week and a tutorial week. Week seven was delivered by the Careers Department. This meant there were nine weeks of lectures. Over the nine teaching weeks attendance averaged at 26 students per week. The highest week was week four with attendance of 32 out of 33 and the lowest was week ten with 19 students in attendance. Students were emailed if they did 
not attend lectures. This module had a significantly higher attendance than other Sociology modules in previous years.

\section{Evaluation and impact}

The study skills module was evaluated through semi-structured interviews with the students, an interview with both the subject lecturer and learning development lecturer and analysis of the self-evaluation assessment. As this module was run as a pilot study, it was not possible to compare marks with the previous year's cohort. However, although it would have been possible to compare the critical review with a similar assignment taken on a Criminology module the previous year, it was decided that the necessity to evaluate variables such as qualification upon entry and WP status would complicate the research study and dilute the focus of the project. It was decided therefore that the impact of the Criminology and Sociology Skills module would be measured through three key areas: semi-structured interviews with the single honours Criminology students (16 out of the 33 cohort); the comments and grades from the self-evaluation assessment; and a semistructured interview with the subject lecturer and learning development lecturer. Ethical approval was received from the university to conduct this research and participating students consented to share the findings.

An average grade mark was also obtained by comparing the first assignment (critical review) with the results for section b of the second assignment (self-evaluation). These two assignments were chosen for evaluation because they were both marked by the learning development lecturer. The average mark for the critical review, which was submitted in week 7 , was $50.25 \%$ while the average mark for the self-evaluation, handed in during week 13 , was $62.37 \%$. The marking criteria was judged by the student's engagement with the 'implicit aims' of the module (1-6) and their ability to understand their development as learners and the need to develop strategies for continuous self-reflection. In the process of marking these assignments, it became clear that a unique marking criteria may have to be developed for future delivery of the module for the purposes of including not only the 'objectives' of the module but the 'implicit aims' as well.

In terms of impact, it was clear that students had benefitted from the skills and expertise of both the subject and learning development lecturer and were highly appreciative of the 
module, acknowledging that the skills gained were an excellent foundation for university study which had significantly enhanced their confidence. Apart from academic skills, another related advantage of the module was the benefit of discussing work, or as one student put it: 'sharing ideas and stuff'. Students reported that whereas previously they had been 'scared' to share, they now realised the learning advantages of 'reading other peoples' work and people reading my work'. Collaborating as a group facilitated an understanding of the need to get 'in the right mindset' for academic work as well as developing key metacognitive skills such as 'mapping out' essay structure. One student added that in most seminars and lectures they just 'go in and out' without talking to their peers, but in the skills module, 'we were more of a group'.

The self-evaluation assignment more specifically reflected the students' awareness of their skills development: time management was referred to in terms of an improved ability to juggle academic study, work and other commitments, as well as a realisation that assignments should be started as early as possible. Some students also demonstrated an increased awareness of their motivation levels and how they could facilitate this by minimising distractions (e.g. phones, social media etc.) and focusing on getting in to the right 'mindset' for studying. Students realised that the skills they were acquiring were transferable beyond the module itself and that the module enabled them to orientate themselves at university.

Overall, the module contributed to student confidence and their sense of belonging and there is some evidence to show impact on retention. In a similar module which ran in the academic year 2015-2016, three out of 21 students withdrew. However, the embedded skills module in 2016-2017 lost just one out of 33 students.

\section{Conclusion}

The embedded skills module for Criminology and Sociology is an example of a highly successful collaboration between Learning Development and the subject lecturer in Sociology. The module has been confirmed as a validated core module for Criminology and has positioned learning development as a normal part of student development at St Mary's rather than a remedial provision for failing students. From a student perspective, the research showed that confidence had improved considerably and that, overall, 
students were less fearful of academic work. The sense of belonging engendered by group work seemed additionally to make students feel more settled and ready for academic work. Both of these factors may have contributed to the lower attrition rate on this module.

\section{References}

Black, M. and Rechter, S. (2013) 'A critical reflection on the use of an embedded academic literacy program for teaching sociology', Journal of Sociology, 49(4) pp. 456-470. https://doi.org/10.1177/1440783313504056

Cottrell, S. (2001) Teaching Study Skills \& Supporting Learning. Basingstoke: Palgrave Macmillan.

Durkin, K. and Main, A. (2002) 'Discipline-based study skills support for first-year undergraduate students', Active Learning in Higher Education, 3(1), pp. 24-39. https://doi.org/10.1177/1469787402003001003

Finch, E. and Fafinski, S. (2012) Criminology Skills. Oxford: Oxford University Press.

Gamache, P. (2002) 'University students as creators of personal knowledge: an alternative epistemological view', Teaching in Higher Education, 7(3), pp. 277-294. https://doi.org/10.1080/13562510220144789

Giddens (1995) Human societies: a reader. Cambridge: Polity Press.

Haggis, T. (2006) 'Pedagogies for diversity: retaining critical challenge amongst fears of 'dumbing down”, Studies in Higher Education, 31(5), pp. 521-535. https://doi.org/10.1080/03075070600922709

Lea, M. R. and Street, B. V. (1998) 'Student writing in higher education: an academic literacies approach', Studies in Higher Education, 23(2), pp. 157-172. https://doi.org/10.1080/03075079812331380364 
McWilliams, R. and Allan, Q. (2014) 'Embedding academic literacy skills: towards a best practice model', Journal of University Teaching and Learning Practice, 11(3), pp. 120. Available at: http://ro.uow.edu.au/jutlp/vol11/iss3/8/

Somerville, E. M. and Creme, P. (2005) 'Asking Pompeii questions: a co-operative approach to writing in the disciplines', Teaching in Higher Education, 10(1), pp. 1728. https://doi.org/10.1080/1356251052000305507

Stankov, L., Morony, S. and Lee, Y. P. (2014) 'Confidence: the best non-cognitive predictor of academic achievement?', Educational Psychology, 34(1), pp. 9-28. http://dx.doi.org/10.1080/01443410.2013.814194

Thies, L.C. (2012) 'Increasing student participation and success: collaborating to embed academic literacies into the curriculum', Journal of Academic Language and Learning, 6(1), pp.15-31.

Wingate, U. (2006) 'Doing away with 'study skills", Teaching in Higher Education, 11(4), pp. 457-469. https://doi.org/10.1080/13562510600874268

Wingate, U., Andon, N. and Cogo, A. (2011) 'Embedding academic writing instruction into subject teaching: a case study', Active Learning in Higher Education, 12(1), pp. 6981. https://doi.org/10.1177/1469787410387814

\section{Author details}

Laura Minogue is a Learning Development Lecturer in the Directorate of Learning and Teaching at St Mary's University, Twickenham.

Dr Carole Murphy is a Senior Lecturer in Criminology and Sociology in the School of Arts and Humanities at St Mary's University, Twickenham.

Dr Kim Salmons is a Programme Director and a Learning Development Lecturer in the Directorate of Learning and Teaching at St Mary's University, Twickenham. 